\title{
Educational supports and career goals of five women in a graduate astronomy program
}

\author{
Ramón S. Barthelemy $\odot,{ }^{1}$ Melinda McCormick $\odot,{ }^{2}$ Charles R. Henderson $\odot,{ }^{3}$ and Alexis Knaub ${ }^{4}$ \\ ${ }^{1}$ Department of Physics and Astronomy, University of Utah, Salt Lake City, Utah 84112, USA \\ ${ }^{2}$ School of Social Work, Western Michigan University Kalamazoo, Michigan 49008, USA \\ ${ }^{3}$ Department of Physics and Malinson Institute for Science Education, Western Michigan University \\ Kalamazoo, Michigan 49008, USA \\ ${ }^{4}$ Department of Physics and Astronomy, Michigan State University, East Lansing, Michigan 48824, USA
}

(Received 25 July 2019; accepted 16 March 2020; published 21 April 2020)

\begin{abstract}
The topic of women in graduate education has been central to many calls for action in increasing diversity and inclusion in science, technology, engineering, and mathematics. The field of physics has been particularly resistant to change in the significant overrepresentation of men, while also being similar to the field of astronomy which has a higher overall representation of women than many other physical sciences. Little research has been done in the field of astronomy to better understand how women can be supported in other physical sciences. This paper presents an analysis of five women students in a U.S. astronomy graduate program. The results indicate the women in this study relied on student-student collaboration to succeed through their coursework and exams, while faculty and post-doctorate support were critical for their research perseverance. Furthermore, the career goals of these successful students indicate the importance of considering multiple life goals in determining a student's pathway, and potentially suggests that the way faculty careers progress needs to be reconsidered if the field wants more diverse faculty and role models.
\end{abstract}

DOI: 10.1103/PhysRevPhysEducRes.16.010119

\section{INTRODUCTION AND LITERATURE REVIEW}

Calls for improved equity and inclusion in the field of physics have been prominent in literature and policy reports for decades [1-7]. However, this research has largely ignored graduate education, which is a crucial step in creating faculty mentors and industry leaders for future generations of students [8-10]. Recently, the National Academies of Science laid out recommendations for supporting graduate students through focusing on better mentorship, collecting data, and ensuring inclusivity, among others [11]. Physics is a particularly important field to study because of its persistent low numbers of women and people of color, which has been well documented [12]. However, within the field of physics exists the subfield of astronomy, which has been known to have higher overall representations of women as compared to other physical sciences (see Figs. 1 and 2) [12,13]. Astronomy may provide a key to understanding how other physical science disciplines can increase their representation of women in graduate programs and eventual faculty positions.

Published by the American Physical Society under the terms of the Creative Commons Attribution 4.0 International license. Further distribution of this work must maintain attribution to the author(s) and the published article's title, journal citation, and DOI.
A complication with increasing the number of women graduates who can become future mentors is considering this institutional aim with the goals and priorities of individual students. There is a fine balance that must be met to recruit and retain underrepresented students in academia while also supporting and preparing them for a variety of careers. The reality, too, is that higher education needs to consider preparing students for nonacademic careers, because there are not enough faculty positions for all graduates [11,16]. Just as Whitten et al. [17] suggested that women may inevitably come to major in physics through a variety of pathways, and not the standard pipeline model $[18,19]$, graduate programs also need to consider the trajectories of students to be a series of pathways [17]. This idea has recently gained some traction in the literature, but graduate programs have largely not taken note $[11,20]$. What is clear is that careful consideration of mentoring and student preparation are necessary to achieve equity in graduate programs through policy and thorough implementation.

\section{A. WOMEN IN PHYSICS (AND ASTRONOMY)}

The women in the physical sciences question has been considered in the literature, with some climate studies dating back to the 1990s demonstrating a chilly climate experienced by women $[6,7]$. In one study, the challenges faced by students were so significant that the authors 
- Undergraduate Degrees Conferred (2010)

Graduate Degrees Conferred (2010)

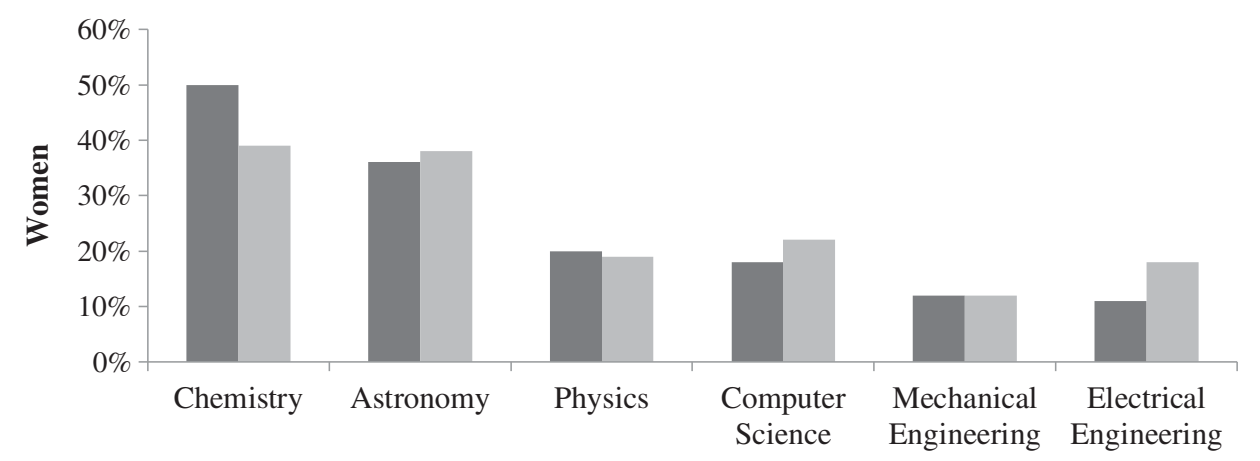

FIG. 1. Percent of women being conferred degrees in the physical sciences at the time of the interviews [14].

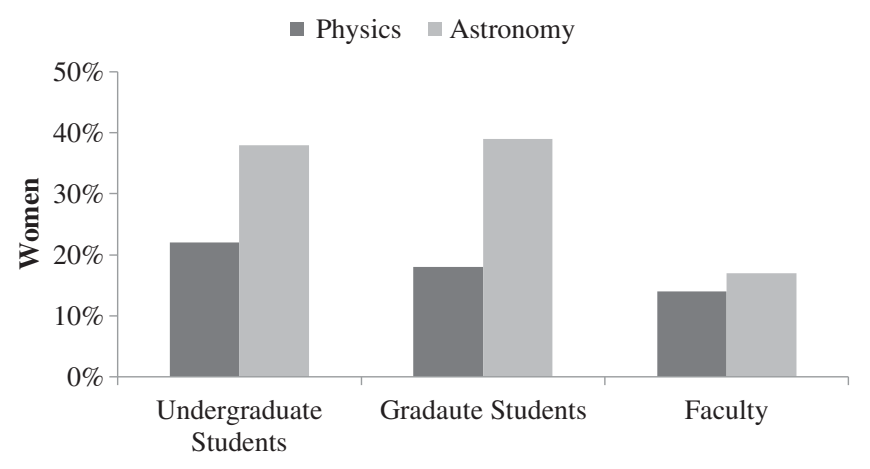

FIG. 2. Percent of women at various stages of physics and astronomy educational pathways at the time of the interviews [15].

labeled successful students as survivors [7], which tacitly implies trauma in the graduate experiences of the participants. Other work has outlined why students pursue graduate education and differential outcomes for men and women [21]. Problematically, the bulk of this work has been done within the gender gap paradigm, that compares women to men while making the underlying assumption that men are the norm to which women need to be compared [22,23]. Almost no work has been done specifically focusing on women in astronomy [24-27].

More recent research by the authors of this paper and others has not focused on gaps, but rather on the individual standpoints of women, to gain knowledge about their experiences and suggest policy changes [24-31]. The research presented below uses the same dataset as earlier papers by the authors [24-26]. This previous work has demonstrated the critical importance of thorough undergraduate preparation [26] and the unfortunate reality of harassment and exclusionary behavior experienced by women in graduate physics and astronomy programs $[24,28]$. Further work has been done outside the purview of physics education research which is also important to consider here, and beyond [32-34].

A salient example of the modern literature on women in the sciences comes from the broader science education community, and builds on ideas from critical race theory
[32,35]. This work is important because it bridges both issues of race and gender through qualitative methodology. In their work Ong et al. [32] found that women of color in higher education science develop "counterspaces" to help them persist and endure the "struggles" they face in their educations. Although this paper looks primarily at women who identify as white, the concept of counterspaces points to the importance of developing places where underrepresented people in the sciences can have a break from the chilly climates and microaggressions that they may be experiencing [32].

\section{RESEARCH GOALS}

This paper seeks to understand which experiences (i) helped support the education of the students, and (ii) which experiences informed the career goals of five women students in a U.S. graduate astronomy program. These participants were in a single graduate astronomy program that had a representation of women faculty higher than the national average at the time and had graduate education policies that promoted cooperation amongst the students in their coursework and qualifying examinations. These specific policies allowed student cooperation in studying in the course, and for their qualifying exam by not applying a curve to any assessments and instead setting a standard metric that all students could meet to succeed. It is not clear if these policies impacted the results below, so focus will be places on these women's experiences as individuals. However, the importance of cooperation did emerge and will be discussed accordingly.

\section{METHODOLOGY}

\section{A. Theoretical framework}

The theoretical framework used in this study is feminist standpoint theory (FST) [36,37]. FST posits that knowledge, in addition to opinions and beliefs, is socially situated. Epistemologically this view situates the understanding, experiences, and knowledge of persons from marginalized groups as significantly different from those 
of persons in the majority or ruling group. This guides inquiry to view marginalized groups (i.e., women and minorities in physics) as having fundamentally different realities within social contexts designed and ruled by the majority. This theory also holds that those within the situation of interest are the "knowers." They are the only ones capable of telling us what their experiences are. Feminist standpoint theory provides the framework for gathering information from women in astronomy graduate programs; to understand these experiences, we must go directly to those who are enrolled in these programs, thus their narratives regarding their experiences in their studies provide the data for this study. In other words, to understand how graduate studies are experienced by women in this field, we must ask them to describe those experiences to us. These descriptions in narrative format then become the data that we analyze.

FST was utilized throughout this study, from the initial design, data collection, analysis, and the write up represented here. The study was designed to only focus on the experiences and lives (standpoint) of women. They were not compared to men, and were focused on only for their unique perspectives and stories. The data were collected using feminist methodologies and FST as well [37]; to operationalize this, all interviews were open ended to allow the participant maximum freedom in their responses $[38,39]$. Participants also had the opportunity to read through their transcripts to ensure that their stories were being accurately told. In the analysis the authors continually reflected on their own positionality to ensure their own biases and standpoints weren't influencing the data analysis. To do this, the first two authors continually discussed their coding and how their perspectives impacted this process. Lastly, in the data representation here full quotes are used. This shows the reader the actual voice of each participant who is included in this write up. In this way FST informed every part of the study from the design to the full implementation.

\section{B. Data collection and analysis}

Data were collected in the form of in-depth, semistructured interviews. These interviews were conversational in form. This promoted an atmosphere that built trust and allowed the participants and the researcher to make meaning of their experiences together [38]. Interviews centered around prompts such as, "Tell me about the pathway that led you to physics (astronomy)." Further probing questions were used, such as, "Tell me more about your relationship with the professors in your classroom." Explicit questions were used near the end of the interview, such as, "How often did you meet with your advisor?" which were informed by previous participant interactions. The first author conducted all of the interviews in person during week-long site visits. Interviews lasted around an hour. All interviews were audio recorded and transcribed verbatim.
These transcripts were sent back to the participants to allow them the opportunity to make changes, or clarify points they deemed necessary. This helped to ensure the reliability of the data while also allowing participants maximum voice in the process. This process also falls in line with FST as it allowed participants to continually ensure that the data taken was reflective of their lived experiences.

Data analysis began as soon as the first interview was conducted. Interviews were read and re-read while constantly comparing them to one another [40]. Codes were applied to interviews looking for lived experiences of the participants, which were then combined to understand overarching themes. These themes were discussed at length by the first two authors and were used to build an understanding of how these participants navigated their pathways through graduate programs in astronomy.

\section{Participants and recruitment}

This data described in this article are part of a larger study where participants had to fit three requirements to participate: (i) Indicate their gender identity as female; (ii) be pursuing a Ph.D. in physics, astronomy, or astrophysics; and (iii) have passed their qualifying examination or equivalent. Students were recruited from researchintensive universities across the United States that had prominent research programs in physics and astronomy. In all, four universities were included in this study, totaling 21 women participants, although the information presented in this paper is specific to one university and five participants. This university has been chosen because of its high representation of women in faculty positions, as it represents a unique case study within the dataset.

The university astronomy department considered in this paper had a combination of high numbers of women faculty and previously had a woman department chair. Women in faculty positions have been suggested to increase the welcoming nature of a departmental climate, promote productivity, and create role models for women students [41-44]. Higher representations of women may also help mitigate the well-documented biases that women face in academia, particularly science [45-48]. At the time of the interviews, the institution was comprised of $35 \%$ women faculty in the department of astronomy, which is over twice the national rate of $17 \%$ (in 2012) [15]. The department head at the time was a man, but a woman had previously held that role, and the department ratio of men to women was frequently mentioned by the participants. It is unclear what, if any, impact this may have had on the students. The data below suggest that for some participants this was important. The department by chance had this higher representation and was not selected for this trait.

All of the participants were well equipped to succeed in a graduate astronomy program due to their preparation as undergraduates. They all did well in their courses, conducted undergraduate research, and some had capstone 
TABLE I. Participant demographics.

\begin{tabular}{lcccc}
\hline \hline & Year & Undergraduate institution & Undergraduate degree & Race \\
\hline Annie & 6 & All women's college & Astronomy \& Physics & White \\
Cyndi & 4 & Research intensive & Physics & White \\
Bishi & 4 & Research intensive & Astrophysics \& Physics & Indian \\
Kate & 3 & Small liberal arts & Physics & White \\
Pat & 3 & Small public university & Business $^{\text {a }}$ & White \\
\hline \hline
\end{tabular}

${ }^{\mathrm{a}}$ Went back to school after working in business to take physics classes before applying to graduate programs in astronomy.

experiences such as traveling to a telescope for data collection. The women primarily represented students in the later stages of graduate school. They were all in their 3 rd, 4th, or 6th years. Four were White, and one participant was Indian. Varying types of undergraduate institutions were represented in these women's backgrounds, from an all-women's college to research-intensive universities. These demographics are summarized in Table I.

\section{Positionality}

The primary researchers conducting analyses were the first two authors. Each author brought a unique perspective to the analysis while recognizing and monitoring their own inherent bias and ignorance. The first author, Dr. Barthelemy, was careful not to project his own experiences as a former graduate student in physics courses onto the experiences of participants. He also recognized his own ignorance with respect to issues such as being a woman in astronomy or parenting. However, he used his experience as a queer Hispanic in physics to relate to the unique issues that nondominant groups face.

The second author, Dr. McCormick, added her perspective to the paper by drawing upon her experiences as a woman and single mother in academia, though she recognized that her position as a former student of sociology and a social worker may be vastly different than that of a student in astronomy. However, this positionality allowed her to view the data from not only different academic domains, but from a different life course position than the first author. This combined to offer more reliability in the analysis by perceiving the interviews and student experiences from multiple perspectives (i.e., that of a minority male in physics, mother in academia, and female graduate student in a university). The third and fourth authors contributed their expertise in physics education research in the design, analysis, and write up of the study.

\section{RESULTS}

The first and second authors worked to determine the codes derived from the data after multiple readings of the interview transcripts. They further discussed the codes until they came to agreement on the codes themselves, as well as the coding schemes which applied to participant narratives. The authors identified that various supports were important to the women's success in their programs. Additionally, the participants' discussions regarding their potential job trajectories provided useful information for consideration when examining academic success.

The results are presented below in two main sections representing the support these women received in pursuit of their graduate degrees and the career goals they intended to pursue. Combined, these sections outline the trajectory that these women traversed as they entered graduate school and began to consider their futures. These women managed to persevere by working with other students and building strong relationships with faculty and researchers. One of the interesting findings that emerged from the participants' narratives was the idea of branching career pathways.

\section{MAIN THEME: SUPPORT}

The support that these women used to navigate their graduate education came largely in two forms: (i) student collaboration and (ii) faculty and post-doctorate research guidance. These subthemes will be outlined below. Students relied on one another to achieve success in their classes and to pass their qualifying exams in the earlier part of their graduate education. As these students progressed into research, they began to rely more on faculty members and post-doctorates to help them in the lab.

\section{A. Student collaboration}

There were two major types of student collaboration that were identified by participants that aided them in their studies: collaboration on assignments and collaboration on studying for the qualifying exam. All of the participants discussed being involved in study groups while completing the assignments in their graduate classes. Cyndi, Pat, and Kate used study groups as a checking mechanism. These participants completed their assignments individually but collaborated with their peers to check answers and discuss items they found confusing:

C: There was a lot of collaboration um, you know the homework we would...do it all on our own until we would run into problems...come find each other and ask each other questions and then if we couldn't figure it out then go ask the professor... 
P...we all would at least try them by ourselves at first and then you get to a point where you're getting stuck on something, that's when we would, oh, you know, meet up and say "How did you deal with this"...

$K$... for the most part we worked together. Um, I would, like, usually go home at night and like work on it as much as I could and then bring what I had to the table and we kind of worked through the sticky points together.

Annie exhibited the subtheme of Female Camaraderie in her graduate study groups. She explained that she "formed a sub group with two of the other girls in [her] class" and they worked on their assignments together late into the night. Annie was the only participant to a show a connection with gender in the creation of her graduate study group.

All participants began to find more autonomy in their work, primarily using each other to check their assignments, rather than complete them. This theme was explicitly stated by Cyndi, Pat, and Kate, while alluded to by Bishi and Annie. The participants may have been transitioning from a complete collaboration in their work to a more focused collaboration that only centered on problems where there was a consensus of confusion. This may show a maturation in learning that must occur for continual success in a Ph.D. program.

The next area of discussion in student collaboration was the participants' experiences with the qualifying examination. The qualifying exam in their department determined whether or not they continued on to be Ph.D. candidates. This exam had to be passed within a student's first three years in the program. Bishi found this experience to be stressful. Her sentiments were also echoed by Kate:

B...they were like probably one of the most stressful things I've ever done. Um, our qualifying exam...

K...(chuckles) The most stressful time in my life.

The qualifying exam was described by Bishi and Kate as being an ordeal they had to overcome. In the discussion of the qualifying exam, Annie reacted with an inflection in her voice as she explained how she "studied really hard for months um, mostly with the same two girls [she] started doing...homework with but also with the rest of [her] class..." Annie re-enforced the stress of the experience described by Bishi and Kate. All of the participants, except for Bishi, reported working with other students in the process of studying for the qualifying examination. Cyndi explained the study pattern her group set up:

C... everyone in my class, so there were 5 of us in my, in my class. We would actually meet here at [café where the interview was taking place] twice a week.

The participants described this stepping stone in their program as a cooperative endeavor. Pat specifically referenced the cooperation and support she had as she studied for the exam:

\section{P...I think our class worked really well together... especially around qual studying time. But um, my class worked really well together. We studied together. I think we're pretty supportive.}

Not only did the students come together to make the qualifying examination a cooperative experience, but the department also set up the process to be inherently collaborative. In some science programs, only a certain number of people can pass the exams that grant access to $\mathrm{Ph} . \mathrm{D}$. candidacy. This was not true for this program, as explained by Cyndi:

C...if you get at least 70\% you're guaranteed to pass, so there wasn't really any sense of competition... I didn't feel any competition with uh, with my classmates at all.

The sense of community that facilitated group work during this time came from both the individual students and the department. The department helped foster this sense of community by developing qualifying exam policies that were inherently collaborative. The participants described a departmental and class environment that was more supportive than competitive. This environment helped these participants persist in the classroom and qualifying exam portions of their graduate education. This allowed them to meet the gate-keeping standard for their continuation in the Ph.D. program.

\section{B. Faculty support}

For these participants an important, but sometimes complicated, source of support came from their professors. The support they received either derived from their coursework or through their relationships with their faculty research advisors. The participant narratives showed three themes of support from advisors that they found particularly meaningful in moving forward in their programs: availability and responsiveness of their advisor(s); quality of the relationship between the student and the advisor(s); and "being pushed" to grow in their studies.

\section{Availability and responsiveness}

Pat and Kate explained that in their coursework and during the time they spent studying for the qualifying exams, the faculty were very helpful when they had questions. Pat described the professors as being willing to "sit down" and discuss astronomy problems. Kate supported this by describing how she could "drop in" to her professors at any time with questions.

Pat's experiences in her coursework were different from her experiences in her research group. She described her 
professor as very busy, so all conversations had to be quick. However, she felt she could go to her advisor when she needed her:

P...she's so busy and she has so many people under her...So it's a little different than my undergrad relationship with my advisor, um, so now, everything is very quick, get to the point...I always feel like I can come to her if I have a problem. If I email her she emails me back right away, which doesn't always happen with other advisors.

Kate's journey to choosing her research advisor involved three faculty. Her first research advisor was mostly absent and had poor communication skills, so Kate decided to switch to another faculty's group. She really enjoyed her new research group because of the advisor. Her new advisor was enthusiastic about research and gave Kate autonomy and agency in her work:

K...he's very encouraging and [helps] you to form your own ideas and speak out, which is definitely part of the transition from undergrad to grad... think for yourself scientifically and not just do what you're told.

Kate eventually had to switch advisors again because of lack of funding. However, she did not enjoy working with her most recent advisor, as she felt she wasn't being pushed enough. Consequently, she switched back to her second advisor to finish her thesis and was hoping the funding situation would work out after they wrote a grant together.

\section{Quality of the relationship}

Cyndi also talked about her process of finding an advisor. She looked for the right personality fit and a person with whom she could easily communicate:

C... I just found advisors that I liked that I thought were very personable and that I got along with really well. I was intentionally picking topics that I had no background or no knowledge...so it was more important to me that I could communicate with my advisor um, when I undoubtedly got stuck on something or had no idea what I was doing.

Bishi had a similar situation with her research advisor; he was not a full faculty member, and she had an official advisor on paper who was a faculty member. Her actual research advisor was at an institution across the country, but she still had a strong relationship with him. He would help her whenever she needed through phone conferences:

B... my relationship with him is really good in that, you know, any time I call him, he always will make time for me. You know, granted, you know, it's obviously not ideal because I'll call vs being right there
Annie's advisor relationship stood in contrast with the other participants. Her advisor was supportive in that she built a strong research community and was involved with the students on an informal basis. She even played on their sports team and invited them camping annually. However, Annie's advisor overtly discouraged her. As Annie was applying to a prestigious position, her advisor told her not to, because she would never get it. Annie also wished her advisor had been there more for her as she was writing her dissertation:

A... I really feel like I've been lost on my thesis...if she had been more active on checking on me and helping me along I think I would have more productive the last couple of months.

\section{3. "Being pushed" to grow}

Cyndi found what she wanted in a nonfaculty researcher who acted as her primary research advisor, while a faculty member facilitated the relationship by being the official faculty advisor on paper. Cyndi liked the large network of collaborators she inherited by working with her current research advisor, and she also felt that he pushed her to achieve more:

C...we talk about what I'm doing, um he reads all of my paper drafts and puts up with all my questions and, what's good is he also really pushes me, um, you know, which sometimes, sometimes gets really irritating, but I know it's good for me and I know that its making me a better, it's definitely making me a better scientist.

Kate and Cyndi both brought up the theme of Being Pushed to do better work. Kate was not being pushed enough and looked for an advisor that would push more, and Cyndi found an advisor that did push her.

The discussion of research advisors with participants revealed complicated interactions that were unique to each student and faculty pairing. Only Annie experienced outright discouragement, but Pat and Kate had issues of access with their first research advisors. Pat stayed with her advisor because of good communication when she was granted access. It is also worth noting that only two of the participants had women advisors, one of whom was the advisor that discouraged Annie.

The gender of the advisor, for these participants, was not as important as the access to resources and time that the individual gave them. In fact, of the five participants, only Kate actually reported often communicating and working with her advisor. The rest of the participants relied on either faculty researchers or post-doctorates to help them in their research. This highlights the importance of faculty advisors who are supportive and friendly, but act as professional mentors and encourage the participants to achieve beyond what they believed they could. This kind of advisor has 
been discussed as being very important for undergraduates [49]. Whitten [50] argued that advisors needed to maintain a friendly but professional relationship with undergraduates, similar to what emerged from some of the interviews with our participants.

\section{Post-doctorate support}

An unexpected source of support for the graduate students interviewed were post-doctorate (post-doc) scholars. In many cases, when advisors or professors were busy or unavailable, many of the women interviewed turned to post-docs in their departments for assistance and hands-on support. Pat discussed how a post-doc was the first person she went to for help understanding results of her research:

P...He was really good about sitting down with me and just sort of, you know giving me different diagnoses I can run to find out what it's doing. So he's been good, he just looked over a draft of my paper and gave me comments, so ...

Kate also discussed the benefits of having post-docs available for assistance:

"[advisor] has a couple of post-docs also which are really helpful to have around because he's also busy, um, and when he's busy I have them to go to."

Annie found it helpful to work with post-docs, particularly when she was in the process of her job search and her faculty advisor was not supporting her in the process:

A... um a post-doc that I know um, that [is my] 'go to' on job stuff like "Oh, how do I write this or write that um, can I see some examples of, like your statement of research or, whatever." And he was, he shared them with me, he also reassured me that you know, people get jobs out of grad school typically.

Bishi and Cyndi also mentioned the support of postdocs, but they were able to access this support during their undergraduate degrees, versus the graduate experiences of the three women mentioned above. The importance of postdocs was an unexpected finding of this research, and those relationships were important to all of the women in terms of their academic success. The main benefit of having postdocs work with students in the doctoral programs was that the post-docs were available, whereas faculty were much less so. The post-docs were able to offer hands-on assistance to the students, not only with problem solving, but also with offering some encouragement and advice for future directions and employment in the field.

The importance of post-docs and their ability to give time to students was highlighted by Bishi when she discussed a post-doctorate she worked for as an undergraduate and for whom she also worked in the summers when he was a faculty member and she was a graduate student. Bishi explained that she managed to build a relationship with him and get training because she met him during his transition from post-doctorate to faculty member:

B...but I was very lucky that at that time he was kind of um, transitioning to, you know his post-doc, his postdoctoral position to faculty...so he's just really busy right now, and so I was able to actually get in before that meaning like we actually developed like a personal relationship and to this day when I go back and work with him I'll just sit in his office and work and like you know be able to just be like "Hey, stop him in the middle of his work and be like help me with this, whereas a lot of students who now meet him aren't able to develop that relationship with him...

\section{CAREER GOALS: BRANCHING PATHWAYS}

When participants discussed their career goals, they identified some struggles with finding their way in the traditional pathway encouraged by academia in graduate programs. Instead, these women seemed to favor pathways that branched away from the traditional models. The typical academic trajectory identified by the women includes a series of post-docs, which involve repeated physical moves, followed by attempts to "maybe" obtain tenure-track faculty positions. Some of the women plan to pursue this track, but others have real reservations about the career trajectory that is held as the standard.

Cyndi is clear about her reservations:

Yeah, well, so my biggest thing against uh, against kind of the traditional academics, you know academic path is, I don't want to have to do 4 post docs and then, you know get a faculty job and then maybe hopefully get tenure like, I just, I don't, want to have to wait, until I'm 40 to get job security, you know? I don't, I don't want to have to move every 2 or 3 years, you know? I wanna be able to lay down some roots and, you know, and eventually, like, start a family and stuff and I can't imagine doing that on, on kind of that traditional, like, career path, and, you know, I like teaching, so I feel like I have a viable alternative career path just like waiting for me, so I just, I don't wanna have to waste the time and energy moving around every 2 years and going from post-doc to post-doc to post-doc and hopefully maybe getting a tenure track job. I just don't want to deal with that (chuckle).

Bishi shares the same train of thought:

I mean the protocol now a days is almost like, you have to get a couple of ... post-doc positions, like, so you get a 1-, 2-, to 3-year post-doc and then you go to a second and then maybe even a third. I, I definitely know people in their 3rd post-doc and then maybe you get your faculty position, you know? 
Annie, on the other hand, accepts the options presented to her.

That's the path. You go to grad school, you get post docs, you become faculty, so I didn't even think about like, sort of like, alternative careers for astronomers, which, there aren't many. Um, it's not like a field where you can go into industry pretty easily. Anyways it, it just seemed natural.

Similarly, Kate is following the traditional path. Kate stated:

I know that like, I'll get my degree, I'm gonna pursue one or two post-doc positions, um, because no matter what I do, I wanna have the science background and have um, I wanna have, you know, the resume to back... the credentials. Exactly. So um, following that, if I'm offered some great faculty position, like, we'll see. I'll kind of take it as it goes.

In spite of Annie and Kate expressing that they will follow the traditional path, both make statements that they're open to other options and plan to see what is available, or what comes along. For Annie, location matters, as well:

I think it will be things like, being able to collaborate with interesting people, having access to students who are really invested in my work and at a certain point I think that it comes in that I don't want to live in the middle of nowhere.

\section{A. "Alternative" pathways and quality of life}

Kate mentions that the discipline is trying to change the stigma about not working in academia, due to the low number of positions available, and mentions that she could see some alternative jobs for herself. "I'm particularly interested in getting more involved in science policy. Um, I like teaching. I like outreach. I could see myself, um, interacting with the public." At the same time, however, she states that she can see herself "at a liberal arts school like my undergrad advisor. I can see myself at a top research institution. Um, yeah, I'm kind of open to any possibilities in the future. It depends on what comes along and what's the most interesting at the time."

In addition to awareness of the uncertain nature of pursuing the dominant career trajectory offered in astronomy, Bishi is also cognizant that she is at a point in life when a significant relationship becomes an eventuality, and she recognizes that it is not fair to ask a partner to move as frequently as an academic career trajectory requires:

You know I'm going to be 29 when I get out of grad school. I mean, who knows, maybe I'll be married. Like, I don't think I could move around a husband 2 to 3 times, you know?... I came into grad school thinking totally astro all the way, but I do realize also as you get older your priorities change.

This is particularly salient to Bishi, who has recently become a first-time aunt:

I think having seen, like, my whole family, all hanging out so much and this new baby-it's like a very exciting time and I feel like I'm missing out.

For Pat, the tenure track is "a little scary." She describes how she views the life of academics:

I, for one, like I said, you have to move so much just to be able to get one of those jobs. And then if you do get one, there's still a ton of work involved. It's, you know, it's a little, it's a little intimidating, I guess. I don't know, it's not very conducive to a family life, I feel, and so, sort of as you get older, you realize that a bit more and.... I don't think it's really good for kids moving every two years. And then, just the amount of work required to get tenure. I mean, I see these postdocs, I mean, these young professors, who are in here every night, every weekend. I mean, you know?

Even though these women are committed to their love of astronomy, they are also aware, as Bishi stated above, that their priorities may change and that they may form relationships and want to have families. And, as Pat stated above, the expected academic trajectory is not very family friendly. All of the women, however, think about what they want to do with their lives and how to balance their career needs with their needs for relationships and family connections.

K: Like, do I want to have kids? Do I not want to have kids? I want to experience a lot, I want to travel. Um, at this point in my life, I don't really see myself settling anytime soon um, but I know that could change really fast. So I don't look too far ahead on that front.

A: Um, I'm not sure if I want to have kids. My current boyfriend doesn't necessarily... because I feel that way strongly now, I doubt that in my near future I'll change my mind. Sure I may change my mind in 5 years but, I'll cross that bridge when I come to it.

Cyndi describes the difficulties she sees of trying to have a family life while pursuing the academic path:

C: I mean just from you know like grad students and post docs who, who have done that, I mean, it's really, really hard, um, and especially if you think, you have to move around constantly, you're not going to ever have like friends or family to, like, be around to help you out... most of the post-docs I know come from the claim that there's no child care, there's no affordable childcare, you know, anywhere, so that's a problem. And then, you 
know, assuming I stay with my, my current partner, like, we're both scientists, so we both have to deal with that, which would make it twice as hard. So I just, I just don't want to deal with it (chuckle). There are other things that are more important to me than my career, so.

Because of the lack of tenure-track faculty positions in astronomy, compared to the number of doctoral students, there are good reasons for these women to consider alternative careers, although, as Kate stated, there is a stigma that comes with leaving academia:

$K$ : I went to the meeting (AAS) in January and they had um, a bunch of sessions encouraging like um, other career paths, for astronomers, like they're trying to, uh reverse the stigma that leaving academia is selling out, cause there's like this-you get your Ph.D., you go into industry. It's seen as selling out in a lot of ways, or you're just not good enough to stick with it, but, um, there's just not enough jobs there, so, they're trying to reverse that stigma and encourage Ph.D.s to pursue other tracks.

These women are considering "alternative" career pathways in light of the job market and their own personal and professional needs. Bishi's "ideal job" would be to "work on like, some sort of telescope and do that process because I feel like it's a very important, you know very-modeling the way the sky impacts your data, like, that is very a rigorous process, you know... ?" The problem Bishi faces is that this type of work is not recognized as important in the field, in spite of the value she sees in its pursuit and development. Others are considering their career options, and exploring things they find interesting.

A: I definitely, I want to do research and teach. Um, So far I've really liked mentoring students and so I definitely want to be able to have students.

C: I like being able to take what I do and what other people do and making it accessible to somebody who doesn't have a science background. And um, and I think you know science education in general, not just astronomy is, all of it is really important and you know teaching critical thinking skills which is something that, you know we desperately need in this country (chuckle), but I feel like I should teach because I actually enjoy it and I'm good at it, and so I should do it.

When Pat considers what she would like to do, she is obviously experiencing a dilemma due to the mismatch between the preferred career path and her own needs:

P: (Exhale) That's a good question. (laughs) I don't know. I, I, I would like stability, you know, at some point. If, (pause) um, yeah if there is a way to do astronomy and still be able to do that and not, have to move every two years, I don't know what that is right now, it doesn't seem like there are many options. It's like you either, you know, do the tenure track route or, yeah, so I'm sort of looking into maybe there is another option, where you could maybe teach or, I don't know.... I guess going forward I would like to find a way to be able to be involved in astronomy while, while still making, you know, making a little bit of money and having a little stability so, I guess that's more of a future thing.

Kate shares a vision she has of success in the field, describing one of her mentors:

K: She's a woman in physics. She teaches, she is very happy, has a family. I just saw her as the picture of success. Um, and, being at a big research institution now, I found a lot of conflicting views, about like what success is like. Her outcome is often seen like kind of settling for less, because she is not at a big research institution and given big grants, but she's still has a tenure job, is still doing research in her spare time and has like a pretty comfortable life, and I don't understand why that's viewed negatively, because she is in a liberal arts school in some ways. But I think that is the atmosphere being at a big research institution.

The career pathways discussed by the participants highlighted the necessity of understanding women's trajectories in science as pathways and not linear pipelines [17,18]. Instead of the "pipeline" ending in a faculty position, each person's educational journey is a pathway ending in a different but ultimately equally valued career. The women in this study demonstrate this model with the varying interests they show in terms of careers. These interests were often driven by factors outside the walls of the academy and their control. Many women were choosing careers to accommodate their personal lives and potential desires to have a family. Success is defined beyond career for them, in that success also includes family and life outside of academia. In some cases, success also means doing things that do not fall in the traditional line of what academic careers are supposed to be or what are held up as the models.

Some of the women are clear that what they need in life is not compatible with some of those ideals, and they want their needs met, while being able to remain connected to a field they love. Since the pipeline is seen as too limiting or too uncertain for such a substantial life investment, these women are attempting to create career pathways for themselves which allow them to meet multiple needs in their lives, and which give them a greater sense of balance.

\section{B. Limitations and further research}

The major limitation of this work is the small number of participants used in this paper. Though few, their experiences and stories were rich with information and gave light to their lived realities within a department of 
astronomy. Another limitation was that our data collection was also confined to one interview. It is possible that with follow-up interviews more codes and themes would have emerged that may have further shaped the analysis. With the aid of member checking, our interviews can at least be said to be reliable and true reflections of our participant's lives [40]. Finally, our participants were in a department that was arguably female friendly, meaning their experiences could be unique to the overall experience of women in astronomy. Therefore, our sample may be small in number, but it also elucidates women's success in graduate programs. Our sample was also majority white, and would have benefited from the perspectives of more women of color.

These limitations suggest that future work may want to focus on large numbers of women in astronomy to gain a better understanding of how women persist in the field. Taking data from many different kinds of institutions with varying representations of women in faculty as well as the student body would give a clearer view of the experiences and career goals of women. It may be interesting to see how career goals change by institution type, representation of women in astronomy, and experiences of women in graduate school.

To our participants, the role of support was imperative; future work may also want to expand upon these findings and investigate support structures of women in astronomy further. In any case, new investigations need to ensure the true voices of women are being heard and that their experiences are correctly represented. In this vein, it is imperative that methodologies include more than just quantitative data (e.g., interviews or open-ended questions) and that they employ more encompassing frameworks than a simple comparison between the experiences of men and women in science degree programs.

\section{DISCUSSION}

\section{A. Educational supports}

We found that there were several factors that may have served as educational supports for the women in this study. First, the presence of a larger number of women faculty and leaders in the department made the department feel woman friendly to some participants. Second, the type of qualifying exam adopted by the department allowed the students to engage in collaboration with one another instead of competition. Third, advisors and faculty supports were available to the students and helped them navigate their graduate programs and research expectations. Finally, post-docs played an important role by being more easily accessible resources, providing hands-on training, and sharing information related to continuing in the field. These were not necessarily intentional actions by the department to support women, but they came together in these participants' lives to uplift their educations.
Research on undergraduate women in physics $[17,49,50]$ and specifically women of color in physics $[31,33]$ have also pointed to the importance of having multiple forms of support to encourage women in physics. The work of Whitten et al. [17,49,50] emphasized the importance of building community and allowing for women students to have opportunities to do research and build professional relationships with faculty. Similarly, Johnson et al. [31] demonstrated the importance of making sure women of color do not feel isolated, with one participant specifically pointing to the importance of encouragement she received from many people in the department. Ong et al. [32] also emphasized the importance of the creation of spaces to counteract the struggles faced by women of color in the sciences. Similarly, the women in this study created study partnerships and relationship with nonresearch mentor advisors in order to navigate their trajectories.

\section{B. Career goals: Pathways into varying definitions of success}

Although the women identified many supports that helped them succeed in their graduate programs, the women identified they could have used more support in terms of knowledge of viable career options beyond the academic trajectory. Since the path described by Cyndi and Bishi includes multiple post-doctoral positions, a lack of stability, and no guarantee of future university employment, many of these women were uncertain what their careers would look like. Coupled with this uncertainty was a "stigma" around pursuing non-research-intensive university positions, which Kate identified as an issue that the field was starting to recognize and address at professional conferences. This same concern has been seen in other astronomy education literature focused on graduate education [51]. Gonsalves [27,51] similarly found that two women astrophysics Ph.D.s found their own pathways to success by focusing less on research and building their identities through teaching.

What we heard from many of the women in astronomy in this study is that the accepted path (pipeline) feels too costly when weighed against their other needs. They mention things like "having a life," forming partner relationships, and possibly having children. This sentiment has been echoed by women in physics who wanted more role models who demonstrated a career and life balance [42].

Some of the women in our study see the definition of success in the field as too narrow and wonder why choices other than the academic career path are viewed with disdain. Teaching at liberal arts colleges and doing research on the side while working with students seems like an acceptable career choice to some of these women, but they know that choice carries stigma. Comparatively, this was a similar career path that fulfilled the lives of two women astrophysics Ph.D.s in Canada [51]. For others, like Bishi, the idea that only certain areas of focus are considered 
worthwhile subject areas is problematic, since there are valid scientific questions to be answered through pursuit of knowledge in many areas which, for some reason, have been deemed unacceptable for graduate work.

From all of this, we see that although the love of the field of study is evident with these women, as is their ability to be successful, the broader academic message continues to encourage the pursuit of the academic trajectory via the pipeline. These women, however, want varied pathways. They want some recognition that life outside academia also has value and that healthy people who value their well being want more balance in their lives than the pipeline model allows [25].

\section{Implications for other physical science fields}

Viable lessons exist in this dataset to motivate and inform policy. A clear standout is the importance of designing programs around collaboration instead of competition. These women were allowed to work together and were only in competition with their knowledge of the content for a passing grade. This idea, combined with the importance of the research support they gained from faculty and postdoctorates, suggests the importance of institutionalizing multitiered mentoring [52]. Instead of hoping students build these mentoring networks on their own, departments should seek to create practices that foster them for students upon entry into their graduate studies.

Lastly, it is clear from both the literature and the lives of these women that departments need to consider how they can hire faculty that can help train students for a variety of careers. In addition to employing mentors that have varied experiences, departments should also provide professional development to educate students on their employment potential beyond post-doctorate positions and academia.

\section{CONCLUSION}

This study presents the one of the first looks into the lives of women in astronomy. Our study illuminates the issues faced by women in an environment that had a strong representation of women and promoted cooperation among students coupled with multiple forms of mentorship. It was found that, even in this setting, women still struggled to see themselves as the researchers they were being trained to be. These women desired more from life than being a "lone investigator"; they had other goals and desires that often included plans of a family. If astronomy (and perhaps physics) wants to invite more women into their field, they may need to reconsider the limiting pipeline that men in the field are seen to traverse. Either alternative career pathways should be proposed to students, or the requirements of existing careers may need to be changed to accommodate more women into the field. These changes could potentially support men as well, making them beneficial for everyone.

\section{ACKNOWLEDGMENTS}

The authors would like to thank the Michigan Space Grant Consortium and the Michigan Advancement for the Graduate Experience and Professoriate for their financial and professional support in pursuit of this project.
[1] N. Ackerman et al., LGBT+ inclusivity in physics and astronomy: A best practices guide, arXiv:1804.08406.

[2] M. Lorenzo, C. H. Crouch, and E. Mazur, Reducing the gender gap in the physics classroom, Am. J. Phys. 74, 118 (2006).

[3] L. Kost, S. Pollock, and N. Finkelstein, Characterizing the gender gap in introductory physics, Phys. Rev. ST Phys. Educ. Res. 5, 010101 (2009).

[4] L. Kost-Smith, S. Pollock, and N. Finkelstein, Gender disparities in second-semester college physics: The incremental effects of a "smog of bias", Phys. Rev. ST Phys. Educ. Res. 6, 020112 (2010).

[5] L. Kost-Smith et al., Replicating a self-affirmation intervention to address gender differences: Successes and challenges, in Proceedings of the 2011 Physics Education Research Conference, edited by N.S. Rebello, P. V. Engelhardt, and C. Singh (AIP, New York, 2011).

[6] M. Dresselhaus, J. Franz, and B. Clark, Improving the Climate for women in Physics Departments: A Program of Site Visits Funded by the National Science Founda- tion (The American Physical Society and the American Association of Physics Teachers, College Park, MD, 1995).

[7] C. Hollenshead, P. Soellner-Younce, and S. A. Wenzel, Women graduate students in mathematics and physics: Reflections on success, J. Women Minorities Sci. Engin. 1, 63 (1994).

[8] N. C. Chesler and M. A. Chelser, Gender-infromed mentoring strategies for women engineering scholars: One establishing a caring community, J. Eng. Educ. 91, 49 (2002).

[9] S. Kelly and J. H. Schweitzer, Mentoring within a graduate school setting, Coll. Stud. J. 33, 130 (1999).

[10] H. R. Tenenbaum, F. J. Crosby, and M. D. Gliner, Mentoring relationships in graduate school, J. Vocat. Behav. 59, 326 (2001).

[11] National Academies of Science, and Medicine, Graduate stem education for the 21st century (National Academies of Sciences, Engineering, and Medicine, Washington, DC, 2018).

[12] National Science Foundation, Women, minorities, and persons with disabilities in science and engineering (National Science Foundation, Washington, DC, 2019). 
[13] AIP, American institute of physics statistical research center (AIP, New York, 2014).

[14] National Science Foundation, Women, Minorities, and Persons with Disabilities in Science and Engineering (National Science Foundation, Washington, DC, 2012).

[15] AIP, American Institute of Physics Statistical Research Center (AIP, New York, 2012).

[16] Y. Xue and C. Larson, Stem crisis or stem surplus? Yes and yes, in Monthly Labor Review (U.S. Bureau of Labor Statistics, Washington, DC, 2015).

[17] B. L. Whitten et al., What works for women in undergraduate physics and what we can learn from women's colleges, J. Women Minorities Sci. Engin. 13, 37 (2007).

[18] C. J. Blickenstaff, Women and science careers: Leaky pipeline or gender filter?, Gender Educ. 17, 369 (2005).

[19] A. V. Maltese and R. H. Tai, Pipeline persistence: Examining the association of educational experiences with earned degrees in stem among us students, Sci. Educ. 95, 877 (2011).

[20] C. N. Fuhrmann, D. G. Halme, P. S. O'Sullivan, B. Lindstaedt, and V. Siegel, Improving graduate education to support a branching career pipeline: Recommendations based on a survey of doctoral students in the basic biomedical sciences, CBE Life Sci. Educ. 10, 239 (2011).

[21] Z. Hazari et al., Motivation toward a graduate career in the physical sciences: Gender differences and the impact on science career productivity, J. Coll. Sci. Teach. 41 (2012).

[22] A. L. Traxler, X. C. Cid, J. Blue, and R. Barthelemy, Enriching gender in per: A binary past and complex future, Phys. Rev. ST Phys. Educ. Res. (2016).

[23] A.L. Traxler et al., Gender fairness within the force concept inventory, Phys. Rev. Phys. Educ. Res. 14, 010103 (2018).

[24] R. S. Barthelemy, M. McCormick, and C. Henderson, Gender discrimination in physics and astronomy: Graduate student experiences of sexism and microaggressions, Phys. Rev. ST Phys. Educ. Res. 12, 020119 (2016).

[25] R. Barthelemy, M. McCormick, and C. Henderson, Barriers beyond equity: An exploratory study of women graduate students' career pathways in astronomy, Int. J. Gender Sci. Technol. 7, 57 (2015).

[26] M. McCormick, R. Barthelemy, and C. Henderson, Women's persistence in undergraduate astronomy: The roles of support, interest, and capital, J. Women Minorities Sci. Engin. 20, 317 (2014).

[27] A.J. Gonsalves, Exploring how gender figures the identity trajectories of two doctoral student in observational astrophysics, Phys. Rev. ST Phys. Educ. Res. 14, 010146 (2018).

[28] R. Barthelemy, M. McCormick, and C. Henderson, Understanding women's gendered experiences in physics and astronomy through microaggressions, in Proceedings of the 2014 Physics Education Research Conference, Minneapolis, MN (AIP, New York, 2014).

[29] A. T. Danielsson, Exploring woman university physics students "doing gender" and "doing physics, Gender Educ. 24, 25 (2012).

[30] A. T. Danielsson, Gender in physics education research: A review, in Never Mind the Gap: Gendering Science in Transgressive Encounters, edited by M. Blomqvist and E. Ehnsmyr (University Printers, Uppsala, Sweden, 2010).

[31] A. Johnson, M. Ong, L. T. Ko, J. Smith, and A. Hodari Common challenges faced by women of color in physics, and actions faculty can take to minimize those challenges, Phys. Teach. 55, 356 (2017).

[32] M. Ong, J. M. Smith, and L. T. Ko, Counterspaces for women of color in stem higher education: Marginal and central spaces for persistence and success, J. Res. Sci. Teach. 55, 206 (2018).

[33] M. Ong, Body projects of young women of color in physics: Intersections of gender, race, and science, Soc. Probl. 52, 593 (2005).

[34] K. Rosa and F. M. Mensah, Educational pathways of black women physicists: Stories of experiences and overcoming obstacles, Phys. Rev. ST Phys. Educ. Res. 12, 020113 (2016).

[35] D. Soloranozo, M. Ceja, and T. Yosso, Critical race theory, racial microaggressions, and campus racial climate: The experiences of African American college students, J. Negro Educ. 60 (2000).

[36] S. N. Hesse-Biber, Handbook of Feminist Research: Theory and Praxis (SAGE Publications, Thousand Oaks, CA, 2007).

[37] S. Harding, Feminist standpoint epistemology, in The Gender and Science Reader, edited by M. Lederman and I. Bartsch (Routledge, New York, NY, 2001).

[38] S. Reinharz, Feminist Methods in Social Research (Oxford University Press, New York, 1992).

[39] A. Brooks, Feminist standpoint epistemology, in Handbook of Feminist Research: Theory and Praxis, edited by S. N. Hesse-Biber (SAGE Publications, Thousand Oaks, CA, 2007).

[40] K. Charmaz, Constructing Grounded Theory (SAGE Publications, Thousand Oaks, CA, 2006).

[41] R. R. Callister, The impact of gender and department climate on job satisfaction and intentions to quit for faculty in science and engineering field, J. Technol. Transf. 31, 367 (2006).

[42] J. M. Curtin, G. Blake, and C. Cassagnau, The climate for women graduate students in physics, J. Women Minorities Sci. Engin. 3, 95 (1997).

[43] S. E. Page, The Difference: How the Power of Diversity Creates Better Groups, Firms, Schools, and Societies (Princeton University Press, Princeton, NJ, 2007).

[44] S. E. Carrell, M. E. Page, and J. E. West, Sex and science: How professor gender perpetuates the gender gap, Quart. J. Econ. 125, 1101 (2009).

[45] C. Wenneras and A. Wold, Nepotism and sexism in peerreview, Nature (London) 387, 341 (1997).

[46] F. Trix and C. Psenka, Exploring the color of glass: Letters of recommendation for female and male medical faculty, Discourse Soc. 14, 191 (2003).

[47] R. E. Steinpreis, K. A. Anders, and D. Ritzke, The impact of gender on the review of the curricula vitae of job applicants and tenure candidates: A national empirical study, Sex Roles 41, 509 (1999).

[48] C. A. Moss-Racusin, J. F. Dovidio, V. L. Brescoll, M. J. Graham, and J. Handelsman, Science faculty's subtle 
gender biases favor male students, Proc. Natl. Acad. Sci. U.S.A. 109, 16474 (2012).

[49] B. L. Whitten et al., "Like a family": What works to create friendly and respectful student-faculty interactions, J. Women Minorities Sci. Engin. 10, 229 (2004).

[50] B. L. Whitten et al., What works? Increasing the participation by women in undergraduate physics, J. Women Minorities Sci. Engin. 9, 1 (2003).
[51] A.J. Gonsalves, Exploring how gender figured the identity trajectories of two doctoral students in observational astrophysics, Phys. Rev. ST Phys. Educ. Res. 14, 010146 (2018).

[52] R. Barthelemy, How can I set up an effective mentoring program to support students in my department? (PhysPort, 2016). 